\title{
Effect of dietary probiotic Pediococcus acidilactici on antioxidant defences and oxidative stress status of shrimp Litopenaeus stylirostris
}

\author{
Mathieu Castex ${ }^{\mathrm{a},}{ }^{\text {*}}$, Pierrette Lemaire $^{\mathrm{a}}$, Nelly Wabete $^{\mathrm{a}}$ and Liet Chim ${ }^{\mathrm{a}}$ \\ a IFREMER, Département Lagons, Ecosystèmes et Aquaculture Durable (LEAD/NC), Campus de l'IRD, Anse \\ Vata, BP 2059, 98848 Nouméa Cedex, New Caledonia \\ *: Corresponding author : Mathieu Castex, Tel.: +687 3525 76; fax: +687 3511 77, email address : \\ Mathieu.Castex@ifremer.fr
}

\begin{abstract}
:
In this study we evaluated the effects of the probiotic Pediococcus acidilactici MA18/5M on shrimp, Litopenaeus stylirostris (also called Penaeus stylirostris), first on antioxidant defences and secondly on the oxidative stress status in the shrimps' haemolymph and digestive gland.

We conducted two experiments with the same protocol in which shrimps were fed two diets for three weeks: a control diet and a probiotic diet containing $1 \mathrm{~g}$ of live $P$. acidilactici MA18/5M kg ${ }^{-1}$. In the first experiment, the shrimps were found to be healthy over the trial period; no mortalities and nondetectable signs of infection were recorded. These resulted in high final survival rates (above $90 \%$ in both treatments). On the other hand, during the second trial, carried out at a period of increased risk for an outbreak of the summer syndrome, higher mortalities were recorded, associated with high $V$. nigripulchritudo prevalence and loads in the shrimp haemolymph. In healthy shrimps (trial 1), no detectable response of the antioxidant defence system and of oxidative stress bio-indicators were observed. However, feeding the probiotic significantly increased the total antioxidant status (TAS) and glutathione peroxidase activity, while all other parameters remained significantly unchanged.
\end{abstract}

In the shrimps exposed to $V$. nigripulchritudo (trial 2), the antioxidant response was characterized by higher antioxidant enzyme activities (superoxide dismutase and catalase) and higher oxidative stress level in the digestive gland (higher oxidized/reduced glutathione ratio, higher malondialdehyde and carbonyl protein contents) compared to levels found in trial 1. However, shrimps fed the probiotic diet exhibited (i) significantly higher final survival rates $(67 \pm 3 \%)$ compared to the control $(47 \pm 4 \%)$ and (ii) a lower prevalence of $V$. nigripulchritudo throughout the trial. Moreover, the antioxidant response and the oxidative stress level recorded in the digestive gland with shrimps submitted to the probiotic diet were lower.

In the light of these results, we confirm that $P$. acidilactici enrichment in shrimps' diet seems an effective way of reducing the susceptibility of shrimps to bacterial pathogens.

Keywords: Shrimps; Probiotic; Oxidative stress; Antioxidant defences; Vibriosis 


\section{Introduction}

Marine shrimps, like other aquatic animals, are constantly threatened by micro-organisms such as fungi, bacteria and protozoa, which can greatly affect their health and well-being. Under farming conditions, pathogen pressure can be higher leading, in some cases, to dramatic crop failures, as observed over the past three decades with marine shrimp cultures affected by vibriosis (Lightner, 1988; Lin, 1995).

Shrimp farming in New Caledonia today faces two main challenges in terms of diseases implicating bacterial pathogens: the "Syndrome 93" (Mermoud et al., 1998) and the "Summer syndrome" (Goarant et al., 2006). The latter phenomenon is causal linked to infectious identified to be due to strains of V. nigripulchritudo (Goarant et al., 2006). In recent years, biological control of these diseases, affecting aqua-cultured species especially bacteriological disorders including environmentally friendlier methods such as the use of probiotics, has become an important subject of investigations (Gatesoupe, 1999; Verschuere et al., 2000; Irianto and Austin, 2002; Vine et al., 2006). Recent works carried out in farmscaled studies have demonstrated the beneficial effects of feeding the probiotic strain, Pediococcus acidilactici MA18/5M, to shrimps Litopenaeus stylirostris (also called Penaeus stylirostris) naturally infected with Vibrio nigripulchritudo (Castex et al., 2008).

Apart from pathogen pressure, reared shrimps are also subject to temperature changes and other environmental perturbations which can severely affect their physiological state (Le Moullac and Haffner, 2000; Wabete et al., 2008). An emerging field of study in physiology of aquatic species is therefore increasingly focusing on "oxidative stress", especially since many authors have reported the effect of environmental perturbations on oxidative stress. Such studies include elucidation of the presence of a wide range of contaminants (xenobiotics) (Winston and Di Giulio, 1991; Livingston, 2001; Manduzio et al., 2005; Ferreira et al., 2005), UV radiation, hypoxia and hyperoxia (Halliwell and Gutteridge, 1999; ZentenoSavín et al., 2006), and other environmental physico-chemical parameters (Le Moullac and Haffner, 2000; Abele et al., 2002; Lesser, 2006) being linked to changes to physiological states of shrimps

Oxidative stress results from either increased exposure or production by the organism of Reactive Oxygen Species (ROS) or from a decrease in the antioxidant defences due to exposure, resulting in oxidative damage to lipids, protein and nucleic acid. ROS include several reactive oxygen intermediates (ROIs) such as superoxide anion $\left(\mathrm{O}_{2}{ }^{-}\right)$, hydroxyl radical $\left(\mathrm{OH}^{\circ}\right)$, hydrogen peroxide $\left(\mathrm{H}_{2} \mathrm{O}_{2}\right)$ and singlet oxygen $\left(\mathrm{O}_{2}{ }^{\circ}\right)$. ROS are continually produced in animals during normal aerobic metabolism (Livingstone, 2001). However, the rate or amount of ROS production depends on the metabolic rate of the species under consideration and can be increased by environmental stress, as shown for penaeid shrimps (Zenteno-Savín et al., 2006; Wang and Chen, 2006; Cheng et al., 2007; Lemaire and Chim, 2007). The reported exceptionally high oxygen consumption capacity of the shrimp, L. stylirostris (Wabete, 2006) makes this species particularly sensitive to oxidative stress.

ROS production is also implicated in the immune response mechanism to both prokaryotic and eukaryotic pathogens (Adema, 1991). In crustaceans, once a pathogen enters the haemolymph, NADPH-oxidase is activated in the hemocyte of the host, which in turn reduces oxygen and subsequently produces several reactive oxygen intermediates. This process, known as respiratory burst, is well documented for aquatic species and recently demonstrated in penaeid shrimps (Muñoz et al., 2000). The immune system and the antioxidant defence system are closely linked to responses due pathogens and other stressrelated issues that might lead to respiratory burst (Homblad and Soderhall, 1999). It has even been suggested that the antioxidant and oxidative responses could become useful parameters for evaluating the in vivo immune response(s) in cultured organisms exposed to given environmental perturbations due to biotic parameters or pathogenic micro-organisms (Campa-Cordova et al., 2005). 
Many studies have also examined antioxidants pressures in aquatic invertebrates, but few have focused on crustaceans (Holmblad and Soderhall, 1999). With respect to shrimps, most of these studies have evaluated the effect of pollutant or environmental parameters on "oxidative stress" (Gonzalez-Rey et al., 2006; Zenteno-Savín et al., 2006; Li et al., 2008). However, very few have reported the effect of pathogen infection on antioxidant defences in penaeid shrimps (Rameshthangam and Ramasamy, 2006; Liu et al., 2007a; Zhang et al., 2008; Hsiesh et al., 2008). Most of the scientific studies carried out to evaluate the effect of probiotics on aquatic farmed animals, apart from demonstrating improvement in survival and growth of the host species have generally focused on nutrition, antagonism toward pathogens, and immunity of the host (Rengpipat et al., 2000; Alavandi et al., 2004; Li et al., 2007; Rodríguez et al., 2007). However, there are very few articles reporting on the effects of dietary additives on oxidative status of cultured shrimps (Liu et al., 2007b; Chiu et al., 2007).

The aim of the present study was to evaluate, firstly, the possible effect of dietary P. acidilactici supplementation on the antioxidant defences and oxidative stress status in L. stylirostris. This effect was evaluated in two different situations: healthy shrimps and shrimps infected by $\mathrm{V}$. nigripulchritudo. We also looked at oxidative damage to lipids and proteins to evaluate oxidative stress status by measuring respectively malondialdehyde (MDA), which is a commonly used indicator to evaluate lipid peroxydation, and carbonyl proteins which is recently being used as biomarker of oxidative damage to protein in fish (Parvez and Raisuddin, 2005).

\section{Materials and Methods}

\subsection{Shrimps}

The shrimps L. stylirostris used in our experiments were reared semi-intensively (without aeration) in earthen ponds $\left(1000 \mathrm{~m}^{2}\right)$ at the Saint-Vincent station (Ifremer). The ponds were stocked with 20-day post-larvae (PL20), at a density of 20 animals. $\mathrm{m}^{-2}$. It usually takes 3 to 4 weeks for the animals to reach $1 \mathrm{~g}$. Thereafter the growth rate is estimated to be approximately 1 to $1.4 \mathrm{~g}$ per week. The experiments in this study were carried out with shrimps of $12.79 \pm 2.72 \mathrm{~g}$ and $6.2 \pm 0.7 \mathrm{~g}$ for the first and second trials respectively.

\subsection{Feeds tested}

Shrimps were fed an experimental feed produced in the laboratory (Table 1): the ingredients were ground up in a laboratory grinder (Retsch $®)$ with a $1 \mathrm{~mm}$ screen. The meal obtained was mixed with oil and water (30\%) in a horizontal mixer (Mainca ${ }^{\circledR}$ ) until the consistency was suitable for pelleting. The mixture was then extruded in a meat grinder through a $3 \mathrm{~mm}$ die. Next, the entire mixture was dried in a drying oven (Venticell ${ }^{2} 222$ ) until a residual humidity less than $10 \%$ was obtained, and then broken up into pellets of $4-5 \mathrm{~mm}$ in length. The commercial probiotic diet preparation tested was Bactocell ${ }^{\circledR}$ PA 10 (Lallemand Animal Nutrition S.A., Blagnac, France) formulated with live Pediococcus acidilactici MA 18/5 M (Institut Pasteur, Paris, France).

For the treated group, $1 \mathrm{~g} \cdot \mathrm{kg}^{-1}$ of the probiotic (powder form) was top-coated on the laboratory produced feed pellets using $2 \%$ of fish oil as a carrier, giving a final concentration of $1.8 \pm 10^{7}$ CFU and $9.5 \pm 10^{6} \mathrm{CFU}$ of $\mathrm{P}$. acidilactici per gram of diet for trials 1 and 2 respectively. The probiotic concentration in the feed was checked after diet formulation by counting $P$. acidilactici strains on MRS plates using serial dilution. The control diet was also topcoated with $2 \%$ fish oil and, prior to use, checked for possible contamination by the probiotic strain. The feed was then stored in 5 -litre boxes at $20^{\circ} \mathrm{C}$ until use. 


\subsection{Experimental design}

In this study, two trials were conducted. Both trials (trial 1 and trial 2) were carried out using the same protocol. L. stylirostris obtained from the earthen ponds were transferred into 8 circular polyester tanks (capacity $1600 \mathrm{~L}$ ). The animals were caught in the ponds using a cast net and transferred to the tanks in plastic containers $(50 \mathrm{~L})$ filled with seawater. One hundred individuals were put into each tank and acclimatized for one week prior to the beginning of the experiment using a previously described protocol, to reduce stress of transfer and associated subsequent mortalities (Wabete et al., 2006). Each tank was continuously oxygenated by injection of high pressure air and supplied with seawater pumped into the lagoon with a water renewal rate of $200 \%$ per day. Temperature was measured continuously (every hour) using an automatic recording probe (Optic StowAway ${ }^{\circledR}$ Temp; Onset).

From the first day of the trial to the end, shrimps were assigned to two treatments with four replicate $(n=4)$ tanks per treatment: shrimps were fed with the control diet versus the probiotic diet. Shrimps from both treatments were fed ad libitum four times a day and the amount of feed was adjusted daily to minimise left-overs. Following the 22-day feeding period, shrimps at the inter-moult stage were randomly sampled after 12 hours starvation for microbiological and biochemical analysis in the haemolymph and digestive gland.

Both trials were conducted during the summer season with water temperature above $25^{\circ} \mathrm{C}$. The first trial was carried out in early November $\left(25.9 \pm 1.9^{\circ} \mathrm{C}\right)$, with the second carried out in February when the summer syndrome linked to proliferation by $V$. nigripulchritudo is known to occur. Indeed during this period, the temperature is optimal $\left(27.2 \pm 2.0{ }^{\circ} \mathrm{C}\right.$ in this experiment) in terms of encouraging the risk of the outbreak of "summer syndrome" (Lemonnier et al., 2006). Smaller animals $(6.2 \pm 0.7 \mathrm{~g})$, were used in this second trial as outbreaks related to the summer syndrome have been most frequently observed during this phase of shrimp's rapid growth (Lemonnier et al. (2006)).

\subsection{Microbiological count in haemolymph}

When experiments are conducted during the summer season in New Caledonia with sandfiltered sea water, the prevalence and load of $\mathrm{V}$. nigripulchritudo in the haemolymph of the shrimps (healthy and moribund) are systematically determined as a routine measurement, in order to assess the presence and the implication of the Vibrio species if relatively higher mortalities have occurred. In this study, V. nigripulchritudo prevalence and load were determined at the start (day 0), mid-term (day 11) and at the end of the trials (day 22). The haemolymph were collected from the ventral-sinus cavity (venous blood), using a $1 \mathrm{ml}$ sterile needle and syringe, from 5 and 10 shrimps per tank at days 11 and day 22 respectively after rinsing the shrimps with sterile seawater. Samples were then plated on Marine Agar (w/v) 2\% glycerol added (MAG), on which $\mathrm{V}$. nigripulchritudo colonies produce grey to black pigments (Baumann and Schubert, 1984). At day 0, a total of 30 shrimps were sampled and analysed in the same way. Plates were incubated for $72 \mathrm{~h}$ to $96 \mathrm{~h}$ at $29^{\circ} \mathrm{C}$. Putative V. nigripulchritudo colonies were counted and recorded per animal. The prevalence was determined as the percentage of animals presenting at least one $\mathrm{V}$. nigripulchritudo species colony, and the load as the number of colonies per infected animal. During trial 2, moribund shrimps $(n=4)$ were sampled, irrespective of the treatment, and their haemolymph were subjected to haemoculture. 


\subsection{Measurement of oxidative stress parameters}

Antioxidant defenses were measured by the level of production of antioxidant enzymes such as Superoxide Dismutase (SOD), Catalase (CAT) and Glutathione Peroxidase (GPx)), glutathione levels (reduced (GSH) and oxidized (GSSG) forms) and Total Antioxidant Status (TAS).

\subsubsection{Sampling and preservation}

On day 22 in both trials, ten shrimps per tank were randomly sampled in order to measure oxidative stress parameters. Only shrimps in the inter-moult (stage C-D0) were used. This was to minimize internal variations, and because changes in physiological functions are generally observed during the moulting stage in crustaceans. Individual shrimps were caught and $100 \mu \mathrm{l}$ of haemolymph were withdrawn from the ventral sinus cavity using a 23gauge needle and $1 \mathrm{ml}$ syringe. Then $10 \mu \mathrm{l}$ haemolymph of the samples were immediately diluted in $100 \mu \mathrm{l}$ pre-cooled Tris buffer 10mM, 1mM DTPA, 1mM PMSF, pH 7.4 and $25 \mu \mathrm{l}$ was further diluted in $25 \mu$ trisodium citrate buffer $30 \mathrm{mM}, 0.34 \mathrm{M}$ sodium chloride, $1 \mathrm{mM}$ EDTA. Samples were then immediately frozen and stored at $-80^{\circ} \mathrm{C}$ until assays were required to be conducted.

The digestive gland were also removed from sampled shrimps and immediately frozen in liquid nitrogen and subsequently stored at $-80^{\circ} \mathrm{C}$. For the assays, the organs were first defrosted, divided into two parts and each part weighed. One part was homogenized in Tris buffer $10 \mathrm{mM}, 1 \mathrm{mM}$ DTPA, $1 \mathrm{mM}$ PMSF, pH 7.4 and the other part in trisodium citrate buffer $30 \mathrm{mM}, 0.34 \mathrm{M}$ sodium chloride, $1 \mathrm{mM}$ EDTA specifically for Total Antioxidant Status (TAS) determination. The diluted haemolymph and digestive gland homogenates were centrifuged at $4000 \mathrm{rpm}$ for $10 \mathrm{~min}$ at $4^{\circ} \mathrm{C}$ and the supernatants kept at $-80^{\circ} \mathrm{C}$ until required to be analysed. For glutathione assays, the supernatants were neutralised with $6 \%$ metaphosphoric acid before storage.

\subsubsection{Biochemical analysis}

\section{Determination of antioxidant enzyme activity}

Prior to SOD, CAT and Gpx activity and soluble protein determination, all samples were heat-shocked to enable cell disruption. This was achieved by submitting the samples three successive times to $1 \mathrm{~min}$ in liquid nitrogen and defrosting at $37^{\circ} \mathrm{C}$.. Total SOD activity was assayed following the method of Marklund and Marklund (1974) which is based on the autooxidation of pyrogallol. CAT activity was measured following the reduction of $\mathrm{H}_{2} \mathrm{O}_{2}$ at $240 \mathrm{~nm}$ according to Clairbone et al. (1985). GPx activity was assayed, by following the rate of NADPH oxidation by the coupled reaction with glutathione reductase at $340 \mathrm{~nm}$ using an extinction coefficient of $6.22 \mathrm{mM}^{-1} \mathrm{~cm}^{-1}$, according to Günzler and Flohé (1985). The soluble protein content was determined by the Folin phenol method of Lowry et al. (1951) using bovine serum albumen (Sigma Chemical Company, Inc., USA) as standard. All of these methods have been adapted for the micro-plate reader Synergy HT (Bioteck ${ }^{\circ}$ ). Enzymatic activities units were all expressed as specific activities (IU.mg of protein ${ }^{-1}$ ).

\section{Glutathione assays and Total Antioxidant Status determination}

The total amounts of GSH and GSSG were determined spectrophotometrically using 5,5dithio-2-nitrobenzoic acid according to the method of Akerboom and Sies (1981). The 
GSSG/GSH ratio, a valuable biomarker of oxidative stress, positively correlated with oxidative stress level (Storey, 1996), was systematically calculated.

TAS is a quantitative measurement which represents the total contribution from a wide range of antioxidant molecules (Prior and Cao, 1999). As the value increases, the antioxidant defences against free radical reaction increases. Using TAS to detect the actual antioxidant status in crustaceans has been previously limited to evaluations of the effects of astaxanthin (Pan et al., 2003). Total Antioxidant Status (TAS) was determined using the Randox Kit, referred to as the "Total Antioxidant Status Kit" (Randox Co., Antrim, UK). TAS of a sample is a quantitative measurement of the state of balance of various antioxidant components under specified reaction conditions. The kit used allows the measurement of the total amount of blood antioxidants by inhibition of the transformation of 2,2-azino-di-[3-ethylbenzthiazoline sulfonate] $(\mathrm{ABTS} \otimes)$ into the radical cation $\left(\mathrm{ABTS} \AA^{\circ+}\right)$ in the presence of a peroxidase (metmyoglobin) and $\mathrm{H}_{2} \mathrm{O}_{2}$.

\section{Malondialdehyde and carbonyl protein assays}

As an index of lipid peroxidation, we used the formation of TBARS during an acid-heating reaction, which is a widely adopted method previously described by Draper and Hadley (1990). Results were expressed as malondialdehyde (MDA) equivalents (nmol.mg prot $^{-1}$ ). For protein carbonylation, supernatants were incubated at room temperature for $1 \mathrm{~h}$ with 10 $\mathrm{mM}$ 2,4-dinitrophenylhydrazine (DNTP) dissolved in $2 \mathrm{M} \mathrm{HCl}$ to allow DNTP to bind to the carbonyl groups (Levine et al., 1994). Blanks were run with $\mathrm{HCl}$ only. Afterwards, proteins were precipitated with $6 \%$ trichloroacetic acid (TCA) and centrifuged for 10 min at $11000 \mathrm{~g}$. The protein pellets were washed three times with ethanol/ethylacetate (1:1), re-suspended in $6 \mathrm{M}$ guanidine hydrochloride, $50 \%$ formic acid, incubated at $37^{\circ} \mathrm{C}$ until complete resuspension. The carbonyl content was measured spectrophotometrically (Synergy HT, Bioteck) in the resulting suspensions at $370 \mathrm{~nm}$ (molar extinction coefficient $22000 \mathrm{M}^{-1} \mathrm{~cm}^{-1}$ ). The results were expressed as nanomoles of DNPH incorporated.mg protein ${ }^{-1}$. The total protein content was determined for each sample according to Lowry et al. (1951).

\subsection{Statistical analysis}

The data obtained were statistically analysed with the statistical package StatView (SAS Inc., Cary, NC, USA). Percent data (survival rate) were normalised using an arcsine transformation before analysis. For means with homogeneous variance, pair-wise comparisons were obtained using Fisher's Protected Least Significant Difference (PLSD) to determine differences between treatments. When this was not possible, comparisons were made using the Mann-Whitney non-parametric test (for treatment comparison of oxidative stress parameters within the same trial) and the Kruskal-Wallis test (for bacterial load in the haemolymph between sampling times).

\section{Results}

\subsection{Trial 1}

3.1.1. Survival and V. nigripulchritudo prevalence in the haemolymph

No obvious signs of infection or mortalities were detected during the first trial (Fig. 1). Final survival rates were high, as much as $90 \%$, with no differences observed between treatments (Table 2). Final load and prevalence of $V$. nigripulchritudo in the haemolymph were observed 
to be null for both treatments at the three sampling. No single black to grey colony was observed on MAG.

\subsubsection{Probiotic effect on oxidative stress indicators}

TAS in both the haemolymph and digestive gland were significantly higher for shrimps fed the probiotic diet (Table 3). Similarly, GPx exhibited higher specific activity in the treated shrimps compared to the control $(p<0.05)$. There were no differences between the experimental groups with regards to levels of other antioxidant enzymes. With regard to oxidative damage, no significant differences were observed with regards to MDA and carbonyl protein contents in the digestive gland of the animals from both groups (Table 4). Mean values were of $81.6 \pm 7.0 \mathrm{nmol} . \mathrm{g}^{-1}$ for MDA and $4.40 \pm 0.28 \mathrm{nmol}^{\mathrm{mg}}$ protein $^{-1}$ for carbonyl proteins respectively.

\subsection{Trial 2}

\subsubsection{Survival and $V$. nigripulchritudo prevalence in the haemolymph}

One week after the start of the second trial, relatively higher mortalities were observed in all the tanks subject to the experiment. Cumulative mortalities for both the probiotic and the control groups are shown in figure 1 . Two peaks were detected at days 11 and 17, and then mortalities fell but continued until the end of the experiment. During the trial, the number of dead shrimps was found to be lower in the probiotic treatment group (Fig. 1). At the end of the trials, tanks fed the probiotic diet exhibited significant higher final survival rates $(64 \pm 7 \%$

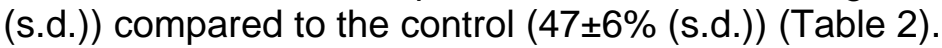

At the start of the trial (day 0 ), no $\mathrm{V}$. nigripulchritudo colony was detected in the haemolymph of the sampled shrimps. At day 11 however, V. nigripulchritudo prevalence was higher than $50 \%$ in the sampled shrimps from both groups; a significantly higher $(p<0.05)$ prevalence and load of $\mathrm{V}$. nigripulchritudo was recorded in the control shrimps (table 2) at this stage. Also, sampled moribund shrimps $(n=4)$ showed a high number of mono-morphic grey to black pigmented colonies on MAG plates which indicated septicaemia due to V. nigripulchritudo (Goarant et al., 2006). At the end of the experiment, V. nigripulchritudo prevalence remained unchanged while the load in the haemolymph was significantly reduced (13.6 \pm 15.9 (s.d.)) compared to day 11 (Table 2). The prevalence of $\mathrm{V}$. nigripulchritudo in the sampled animals was still lower for the probiotic group with an average value of $45 \pm 12 \%$ (s.d.) compared to the control group $(90 \pm 8 \%$ (s.d.)). However, V. nigripulchritudo loads were not significantly different between the two groups at this stage.

\subsubsection{Probiotic effect on oxidative stress indicators}

Total Antioxidant Status in both the haemolymph and the digestive gland of L. stylirostris fed the control and P. acidilactici supplemented diets are presented in Table 3. In shrimps fed the probiotic diet, TAS was significantly higher, particularly in the haemolymph where it was twice that recorded in the control group. Significantly $(p<0.01)$ higher SOD activities in the control treatment were found in the haemolymph and in the digestive gland $(+88 \%$ compared to the probiotic group, Table 3.). Similarly CAT activity for control animals was also higher compared to the probiotic group (Table 3.). On the other hand, GPx activity was lower in the control compared to the probiotic group (Table 3). No significant differences were recorded in GSH content. However, the ratio of oxidized glutathione to total glutathione (GSSG/GSH), for which an increase is considered to be a marker of oxidative stress, was 
significantly higher for the control animals (Table 3). Finally we found that the probiotic treatment group exhibited a significantly lower concentration of carbonyl protein $(p<0.01)$ compared to the control (Table 4). The same trend was observed for the MDA concentration, but the differences between groups were not statistically significant $(p=0.06)$.

\subsection{Comparison of antioxidant defences and oxidative stress parameters between the two trials}

Comparison of the observations on the parameters in the digestive gland between the experimental series revealed the following:

In the control groups (table 3), TAS of the shrimps exposed to V. nigripulchritudo (trial 2) exhibited lower values (-34\%) compared to the healthy shrimps (trial 1). Moreover, antioxidant enzymes (fig $2 \mathrm{~A}$ and $2 \mathrm{~B}$ ) showed higher activity in the shrimps from trial 2, with higher values of $175 \%, 397 \%$ and $402 \%$ for SOD, CAT and GPx respectively; in addition the GSH levels and the GSSG/GSH ratio were also higher ( $+41 \%$ and $+163 \%$ respectively) compared to trial 1.

In the probiotic groups (Table 3), similar but less pronounced trends were observed. Shrimps exposed to V. nigripulchritudo exhibited lower values for TAS (-11.5\%), while SOD, CAT and GPx activities were 50\%, 103\% and 560\% respectively, higher than that for healthy animals. Similarly, GSH levels and the GSSG/GSH ratio were also higher $(+71 \%$ and $+44 \%$ respectively) compared to healthy animals.

With regards to oxidative damage, carbonyl protein and MDA contents in shrimps from the control group in trial 2 were the highest levels recorded (Table 4). In contrast, the groups fed the probiotic diet showed similarly high levels in both trials.

\section{Discussion}

To evaluate oxidative stress status in organisms several strategies have been proposed (Kooter et al., 2004). It is generally recommended to measure: (i) the levels of ROS, (ii) the macromolecules damaged by ROS, and (iii) the primary defence against ROS such as antioxidant enzymes or low molecular weight ROS scavengers. Monitoring the oxidative stress process is complicated since ROS are very reactive and therefore difficult to measure. The association of several biomarkers is therefore regarded as the best optional way to suitably evaluate oxidative stress status. This was chosen in this study. We therefore measured on one hand enzymatic and non-enzymatic antioxidants, and on the other hand, products or macromolecules damaged by reactive oxygen species. All these biomarkers were measured in the digestive gland.

In marine aquatic organisms, it has been reported that the main antioxidant enzymes are generally with higher activity in biotransformation organs as digestive tissues (Livingstone et al., 1992; Lemaire and Livingstone, 1993). We have also, in this study, measured TAS and SOD activity in the haemolymph, since the blood cells of invertebrates are the primary effectors in host defence and are involved in various immune processes such as phagocytosis (Söderhäll and Cerenius, 1998).

\subsection{Antioxidant defences and oxidative stress status in healthy shrimps}

Shrimps from trial 1 showed relatively higher survival rates and no obvious signs of infection with no prevalence of $\mathrm{V}$. nigripulchitudo observed in their haemolymph. This may indicate 
that the shrimps were healthy and that pathogen pressure was particularly low during this trial. In addition, MDA concentrations recorded in the digestive gland were close to 80 nmol.g organ ${ }^{-1}$, and in the same order as concentrations determined previously by our team and by other authors for healthy shrimps reared under comparable conditions $\left(25^{\circ} \mathrm{C}, 37 \mathrm{psu}\right.$ salinity, normoxia) (Zenteno-Savín et al., 2006). Moreover shrimps also exhibited SOD and CAT activities in the same range of values to the ones reported in previous studies carried out in healthy (control) shrimps of the species, P. monodon and L. vannamei (Rameshthangam and Ramasamy, 2006; Li et al., 2008). For example, for L. vannamei reared in experimental tanks, Li et al. (2008) reported mean activities around 2 U.mg protein ${ }^{1}$ and 0.6 U.mg protein ${ }^{-1}$ respectively for SOD and CAT in the digestive gland. These results clearly indicate that the healthy shrimps were not exposed to any oxidative stress resulting in detectable response(s) such as those of anti-oxidative defence systems and or specific tissue damage.

Healthy shrimps fed the probiotic diet did not exhibit any obvious differences regarding SOD and CAT activity, or MDA and carbonyl proteins levels compared to control animals with regards to the conditions of trial 1 . This underlines that under standard conditions and in the absence of any particular stress conditions, probiotic treatment did not seem to have any effects on CAT and SOD activities, contrary to what had been observed with dietary supplementations with $\beta$-Glucans or vitamin E (Campa-Cordova et al., 2005; Liu et al., 2007b). Mourente et al. (2002) concluded that a more direct peroxidative stress (feeding of oxidised oil in this case) is required before clear effects on liver antioxidant enzyme activity could be observed in Sparus aurata $\mathrm{L}$. On the other hand however, in our experiment higher TAS levels in both the haemolymph and the digestive gland, and higher GPx activity in the digestive gland, were observed in the probiotic fed group. Pan et al. (2003) reported increases in TAS level in P. monodon Fabricus juveniles fed for 8 weeks with $71.5 \mathrm{mg} \mathrm{kg}^{-1}$ astaxanthin enriched diet. Our result may indicate that the feeding of probiotic acts in such a way as to increase the antioxidant status of the shrimps. It can therefore be assumed that the probiotic diet may (i) improve the diet utilization (Castex et al., 2008) and contribute to increasing the assimilation of dietary antioxidants from the feed and/or (ii) plays a role in antioxidant activity, as has been reported for other lactic acid bacteria (Kullisaar et al., 2002). These authors hypothesized that the anti-oxidative properties of a Lactobacillus fermentum strain may serve as defensive mechanisms in the intestinal microbial ecosystem and therefore help overcome exo- and endogenous oxidative stress(ess).

Interestingly, previous studies (Castex et al., 2006; Castex et al., 2008) have reported the effects and the persistence of P.acidilactici in shrimp intestinal microbiota, and a recent work by Castex (2009) where molecular techniques (Denaturing Gradient Gel Electrophoresis) were used for certain measurements has indicated that there are changes in the intestinal microbial ecosystem in shrimps where probiotics are fed.

Finally, Kullisaar et al. 2003 has previously shown an increase in the total antioxidant status (TAS) in blood of humans fed L. fermentum fermented goats' milk. Similar events occurring in aquatic species do not seem to have been investigated and therefore will make interesting object of future scientific research.

\subsection{Antioxidant defences and oxidative stress status in shrimps exposed to V. nigripulchritudo}

During the second trial, high mortalities were observed, particularly in the control tanks $(47 \pm 6 \%$ final survival rate). Higher number of $\mathrm{V}$. nigripulchritudo strains were recorded in the sampled (41.5 \pm 16.6 colonies per infected shrimps) and moribund shrimps which suggested involvement of this pathogen with regards to the mortalities recorded during this trial (Goarant et al., 2006). 
Higher activities of the antioxidant enzymes (SOD, CAT and GPX), a higher GSSG/GHT ratio and higher carbonyl protein content observed in trial 2 when compared to trial 1, are suggestive of responses observed to be linked to antioxidant defence systems and higher oxidative stress levels in shrimps exposed to V. nigripulchritudo. These observations lead us to conclude that this Vibrio infection may have led to ROS accumulation (Campa-cordova et al., 2002; Cheng et al., 2007). This is consistent with previous studies showing the induction of respiratory burst, especially production of superoxyde anion, in the haemocytes of shrimps challenged with Vibrio sp. (Liu et al., 2007a). This ROS accumulation could explain the higher anti-oxidative enzyme activity and the oxidative stress observed in this trial.

Liu et al. (2007a) reported a concomitant increase in ROS and SOD activities following $V$. alginolyticus infection. Other authors have also reported a short-term decrease of SOD in both the digestive gland and haemolymph after pathogenic vibrio injection or White Spot Syndrome virus infection (Hsieh et al., 2008; Rameshthangam and Ramasamy, 2006). However, these studies were carried out under different conditions including level of infection, thereby making comparisons difficult: sampling of moribund shrimps, experimental infection (oral versus by injection) and shorter exposure time to pathogens. Hence, researchers at our establishment in New Caledonia are currently working on elucidating short-term evolutions of anti-oxidative defences in L. stylirostris experimentally challenged with pathogenic Vibrio.

\subsection{Probiotic effect on the survival rate, antioxidant defences and oxidative stress status in shrimps exposed to $\mathrm{V}$. nigripulchritudo}

During the second trial, the probiotic fed shrimps exhibited a significantly higher final survival rate $(64 \pm 7 \%)$, which may imply a better resistance to $V$. nigripulchritudo. This argument seems to be consistent with the lower level of prevalence and load recorded in the shrimps' haemolymph. The result agrees with that of our previous studies obtained under pond conditions (Castex et al., 2008). Moreover, we showed in this study that overall, nonenzymatic antioxidant defences, measured by the total anti-oxidant status (TAS), were higher for shrimps fed with the probiotic diet compared to the control. On the other hand, the probiotic fed shrimps presented lower activities of SOD and CAT. This observation could be explained by a lower stimulation of these two antioxidant enzymes. Indeed, the reduction of antioxidant enzymatic activities were, in some cases, associated with decreased oxidative stress and free radical activities (These were based on the fact that the lower oxidative stress, the fewer antioxidant enzymes were produced (Rahmat et al., 2006)).

However, elevated SOD activities have also been reported for aquatic species in response to other environmental perturbations such as high variations in salinity and temperature (Lesser, 2006), bacterial infection or exposure to xenobiotics (Cajaraville et al., 2000). Mourente et al. (2002) reported significantly higher activity of liver antioxidant enzymes (CAT and SOD) in juvenile sea bream fed dietary oxidised oil after 30 days and showed that dietary vitamin E partially offset this effect. Another explanation of a higher TAS and lower SOD and CAT activities in the liver of shrimp fed probiotic may reside in an improved utilization of the diet, more specifically of the carbohydrates. Indeed, in our first study (Castex et al., 2008), and in recent works from our laboratory (in prep.), we showed an increased activity of L. stylirostris's digestive enzymes, especially a amylase activity, when fed a probiotic diet. In shrimps, a amylase with a glucosidase are the two digestive enzymes which control the first step of dietary carbohydrate degradation pathway leading to glucose production and further glycogen synthesis in the liver (Rosas et al., 2002). Interestingly, Lygren and Hembre (2001) reported that in Atlantic salmon an increase in liver glycogen concentration in the liver led to a reduction in liver CAT and total SOD activities. According to these authors, the results observed may be explained by the ability for either the glucose to scavenge OH-radicals (Sagone et al., 1983), or alternatively, the ability of the glucose to 
stimulate increased pentose-phosphate activity (Kashiwagi et al., 1997). Our results with L. stylirostris could corroborate this hypothesis.

In the present study, contrary to the observed lower levels of other enzyme activities measured, GPx activity was found to be higher for the probiotic group. GPx is of central importance in mammals in detoxifying $\mathrm{H}_{2} \mathrm{O}_{2}$ and lipid peroxides, and was found to be present at high levels in the digestive gland of some marine invertebrates (Gamble et al., 1995). The greater GPx activity in the probiotic group compared to the control may be explained by a relatively lower $\mathrm{H}_{2} \mathrm{O}_{2}$ level based on the following considerations: (i) GPx have a higher degree of affinity for $\mathrm{H}_{2} \mathrm{O}_{2}$ than catalase (Kang et al., 2005), and in the presence of low $\mathrm{H}_{2} \mathrm{O}_{2}$ levels, organic peroxides are the preferred substrates for GPx, (ii) GPx is widely distributed in the cell unlike catalase which is located in the peroxisome and functions only when the concentration of $\mathrm{H}_{2} \mathrm{O}_{2}$ is high in the cell and diffuses into the peroxisome (Freeman and Crapo, 1982). The different responses of SOD, CAT and GPx may also indicate a different mechanism for regulation of gene expression for GPx, perhaps related to the fact that GPx is more involved in the removal of organic peroxides and, only to a much lesser extent, of hydrogen peroxide (Mourente et al., 2002; Zhang et al., 2008). Moreover, probiotic fed shrimps exhibited a lower level of oxidative stress as shown by lower GSSH/GSH ratio and carbonyl protein content compared to the control animals $(P<0.001)$.

The determination of carbonyl protein, as a marker of oxidative stress, is quite recent for fish (Parvez and Raisuddin, 2005) and is not commonly used for shrimps. However, oxidative modifications of protein are one of the many consequences of oxidative stress (Stadtman, 1986), and the assay of carbonyl groups in protein provides a convenient technique for detecting and quantifying oxidative stress (Levine et al., 1994). With regards to MDA, probiotic shrimps also exhibited lower levels than the controls but without any significant difference $(p=0.06)$. Interestingly this result can be related to the higher GPx activity recorded in the probiotic group as GPx is involved in the removal of organic peroxides. However, we can assert that the measure of MDA, as a biomarker of oxidative damage to lipids, presents weaknesses with regard to its sensitivity, as recently reviewed by Lykkesfeldt (2007). All these are in support of a lower oxidative stress level in the probiotic shrimps expose to $\mathrm{V}$. nigripulchritudo compared to the controls.

To our knowledge, very few studies with penaeid shrimps have reported probiotic effects on antioxidant defences and oxidative stress status. Recently, Chiu et al. (2007) reported that Lactobacillus plantarum administered at $10^{7} \mathrm{CFU} . \mathrm{g}^{-1}$ of feed was able to induce immune modulation and enhanced immunity ability of L. vannamei, increasing its resistance to V. alginolyticus infection. Indeed, these authors showed enhanced cellular and humoral responses such as phenoloxidase activity, superoxidase activity, clearance efficiency against V. alginiolyticus, and proPO and peroxinectin (PE) mRNA transcription levels in the probioticfed shrimps. Interestingly, they showed that when the probiotic was fed, the respiratory burst in the shrimps' haemolymph were reduced through increase in SOD and PE gene transcription and suggested that L. plantarum may have enhanced antioxidant status of the shrimp concomitantly to increasing the immune response. At this stage where further investigations on the subject are still required to elucidate the possible mode of action, it could however be hypothesized that the observed effect was as a result of the following: (i) a lower production of ROS due to a limitation of the infection level and/or (ii) a higher antioxidant status in the shrimp fed a probiotic diet. Given the observations by Chiu et al. (2007), it would be interesting to study the relationship between anti-oxidative status and immune response under the particular conditions of the current study. 


\section{Conclusions}

Our results indicate that when no particular oxidative stress occurred, $P$. acidilactici supplementation in the diet confers a higher overall antioxidant status (TAS) to the shrimp but seemed to have had little effect on the antioxidant defences. However, exposure of $\mathrm{L}$. stylirostris to $\mathrm{V}$. nigripulchritudo led to antioxidant response characterized here by (i) an increase in some antioxidant enzymatic activities and (ii) an elevated oxidative stress level. Interestingly, the response including levels of oxidative stress observed was reduced in the shrimps fed the probiotic diet. This probiotic effect was linked to lower prevalence and load of Vibrio in the shrimps' haemolymph and higher survival rates. In the light of those results, we confirm that P. acidilactici supplementation in shrimps' diet could be an effective way to reduce the susceptibility of shrimps to bacterial pathogens, as previously shown under pond farming conditions (Castex et al., 2008). Further studies are under way to elucidate probiotic effects on short-term evolution of antioxidant defences and oxidative stress levels in L. stylirostris exposed to experimentally infected pathogenic Vibrio.

\section{References}

Abele D., Heise, K., Pörtner, H.O., Puntarulo S., 2002. Temperature-dependence of mitochondrial function and production of reactive oxygen species in the intertidal mud clam Mya arenaria. J. Exp. Biol. 205, 1831-1841.

Adema, C.M., Van der Knaap, W.P.W., Sminia, T., 1991. Molluscan haemocyte mediated cytotoxicity: the role of reactive oxygen intermediates, Reviews in Aquatic Sciences, 4: 201223.

Akerboom, T.P.M., and Sies, H., 1981. Assay of glutathione, glutathione disulfide and glutathione mixed disulphides in biological samples, Methods Enzymol 77: 373-382.

Alavandi, S.V., Vijayan, K.K., Santiago, T.C., Poornima, M., Jithendran, K.P., Ali, S.A., Rajan, J.J.S., 2004. Evaluation of Pseudomonas sp. PM 11 and Vibrio fluvialis PM 17 on immune indices of tiger shrimp, Penaeus monodon. Fish \& Shellfish Immunology 17, 115120.

Baumann, P., Schubert, R.H.W., 1984. Section 5. Facultatively anaerobic Gram-negative rods, Family II. Vibrionaceae. In: Holt, J.G., Krieg, N.R. (Eds.), Bergey's Manual of Systematic Bacteriology, vol. 1. Williams \& Wilkins Co., Baltimore, MD, pp. 516-550.

Cajaraville, M.P., Bebianno, M.J., Blasco, J., Porte, C., Sarasquete, C., Viarengo, A., 2000. The use of biomarkers to assess the impact of pollution in coastal environments of the Iberian Peninsula: a practical approach. Sci. Total Environ. 247, 201-212.

Campa-Cordova, A.I., Hernandez-Saaveda, N.Y., De Philippis, R., Ascencio, F., 2002. Generation of superoxide anion and SOD activity in haemocytes and muscle of American white shrimp (Litopenaeus vannamei) as a response to $\beta$-glucan and sulphated polysaccharide. Fish \& Shellfish Immunology, 12: 353-366.

Campa-Cordova, A.I., Hernandez-Saaveda, N.Y., Guzmán A.G., Ascencio, F., 2005. Immunomodulatory response in juvenile American white shrimp (Litopenaeus vannamei) exposed to immunostimulants. Ciencias marinas, 31 (4): 661-669.

Castex, M., Chim, L., Wabete, N., Lemaire, P., Usache, V., 2006. Feeding evaluation of probiotic bacteria Pediococcus acidilactici (Bactocell $囚$ ) in sub adult shrimp Litopenaeus stylirostris: microbial, nutritional and zootechnical aspects. Book of AbstractWAS Annual Meeting, 9-13 May 2006. Florenze, Italia.

Castex, M., Chim, L., Pham, D., Lemaire, P., Wabete, N., Nicolas, J.-L., Schmidely, Ph., Mariojouls, C., 2008. Probiotic P. acidilactici application in shrimp Litopenaeus stylirostris culture subject to vibriosis in New Caledonia. Aquaculture, 275: 182-193.

Castex, M. 2009. Evaluation of probiotic bacteria Pediococcus acidilactici MA18/5M on penaeid shrimp Litopenaeus stylirostris in New Caledonia. Thesis presented at the "Institut 
des Sciences et Industries du Vivant et de l'Environnement (Agro Paris Tech)", Ecole doctorale Ecole Doctorale ABIES - Physiology, Nutrition. 400 pp.

Cheng, S.Y., Hsu, S.W., Chen, J.C., 2007. Effect of sulfide on the immune response and susceptibility to Vibrio alginolyticus in the kuruma shrimp Marsupenaeus japonicus. Fish \& Shellfish Immunology, 22: 16-26.

Chiu, C.H., Guu, Y.K., Liu, C.H., Pan, T.M., Cheng, W., 2007. Immune responses and gene expression in white shrimp, Litopenaeus vannamei, induced by Lactobacillus plantarum. Fish \& Shellfish Immunology 23, 364-377.

Clairbone, A., 1985. Catalase. In: R. Greenwald, Editor, Handbook of Methods for Oxygen Radical Research, CRC Press, New York (1985), pp. 283-284.

Draper, H.H., Hadley M., 1990. Malondialdehyde determination as an index of lipid peroxidation. Methods Enzymol, 186: 421-431.

Ferreira, M., Moradas-Ferreira, P., Reis-Henriques, M.A., 2005. Oxidative stress biomarkers in two resident species, mullet (Mugil cephalus) and flounder (Platichthys flesus), from a polluted site in River Douro Estuary, Portugal. Aquatic Toxicology, 71: 39-48.

Freeman, B.A., Crapo, J.D., 1982. Biology of disease. Free radicals and tissue injury. Laboratory investigation, 47 (5): 412-419.

Gamble, S.C., Goldfarb, P.S., Porte, C., Livingstone, D.R., 1995. Glutathion peroxidase and other antioxidant enzyme function in marine invertebrate (Mytilus edulis, Pecten maximus, Carcinus maenas and Asterias rubens). Marine Environmental Research, 39: 191-195.

Gatesoupe, F.J., 1999. The use of probiotics in aquaculture. Aquaculture 180, 147-165.

Goarant, C., Ansquer, D., Herlin, J., Domalain, D., Imbert, F., De Decker, S., 2006. Summer Syndrome in Litopenaeus stylirostris in New Caledonia: Pathology and epidemiology of the etiological agent, Vibrio nigripulchritudo. Aquaculture 253, 105- 113.

Gonzalez-Rey, M., Serafim, A., Company, R., Bebianno, M.J., 2006. Adaptation to metal toxicity: a comparison of hydrothermal vent and coastal shrimps. Marine Ecology 28, $100-107$.

Günzler, A., and Flohé, L., 1985. Glutathione peroxidase. In: R.A. Greenwald, Editor, CRC handbook of methods for oxygen radical research (Vol. 1), CRC Press, Boca Raton, Florida, USA (1985), pp. 285-290.

Halliwell, B., Gutteridge, J.M.C., 1999. Free Radicals in Biology and Medicine, 3rd ed. Oxford University Press.

Holmblad, T., Söderhäll, K., 1999. Cell adhesion molecules and antioxidative enzymes in a crustacean, possible role in immunity. Aquaculture, 172:111-123.

Hsieh, S.H., Ruan, Y.H., Li, Y.C., Hsieh, P.S., Hu, C.H., Kuo, C.M., 2008. Immune and physiological responses in Pacific white shrimp (Penaeus vannamei) to Vibrio alginolyticus. Aquaculture 275: 335-341.

Irianto, A., Austin, B., 2002. Review Probiotics in aquaculture. J. Fish Dis. 25, 633.

Kang, S.W., Rhee, S.G.,, Chang, T.,S., Jeong, W., Choi, M.H., 2005. 2-Cys peroxiredoxin function in intracellular signal transduction, therapeutic implications. Trends Mol Med, 11:571-8.

Kashiwagi A., Nishio Y., Asahina T., Ikebuchi M., Harada N., Tanaka Y. et al. 1997. Pyruvate improves deleterious pentose phosphate pathway and glutathione redox cycle in endothelial cells. Diabetes 46: 2088-2095.

Kesarcodi-Watson, A., Kaspar, H., Lategan, J., Gibson, L. 2008. Probiotics in aquaculture: the need, principles and mechanisms of action and screening processes. Aquaculture, 274: $1-14$

Kooter, I.M., 2004. Inventory of biomarkers for oxidative stress. RIVM report 630111001.

Kullisaar, T.,, Zilmer, M., Mikelsaar, M., Vihalemm, T., Annuk, H., Kairane, C., Kilk, A., 2002. Two antioxidative lactobacilli strains as promising probiotics. International Journal of Food Microbiology, 72: 215- 224.

Kullisaar, T., Songisepp, E., Mikelsaar, M., Zilmer, K., Vihalemm ,T., and Zilmer, M., 2003. Antioxidative probiotic fermented goats' milk decreases oxidative stress-mediated atherogenicity in human subjects. British Journal of Nutrition, 90: 449-456. 
Lemaire, P., Chim, L., 2007. Effect of experimental temperature fluctuations on some "oxidative stress" bio-indicators in the digestive gland of the shrimp Litopenaeus stylirostris. Annual meeting, 9-13 may 2007, Mexic.

Lemaire, P., Livingstone, D.R., 1993. Pro-oxidant/antioxidant processes and organic xenobiotics interactions in marine organisms, in particular the flounder Platichthys flesus and mussels Mytilus edulis. Trends Comp. Biochem. Physiol. 1, 1119-1150.

Lemonnier, H., Herbland, A., Salery, L., Soulard, B., 2006. "Summer syndrome" in Litopenaeus stylirostris grow-out ponds in New Caledonia: zootechnical and environmental factors. Aquaculture 261, 1039-1047.

Le Moullac, G., Haffner, P., 2000. Environmental factors affecting immune responses in Crustacea. Aquaulture 191, 121- 131.

Lesser, M. P., 2006. Oxidative Stress in Marine Environments: Biochemestry and Physiological Ecology. Ann. Rev. Physiol., 68: 253-278.

Levine, R.L.,Williams, J.A., Stadman, E.R., Shacther, E., 1994. Carbonyl assays for determination of oxidatively modified proteins. Methods in Enzymology, 233, Academic Press, New York, pp. 346-357.

Li, K., Zheng, T., Tian, Y., Xi, F., Yuang, J., Zhang, G., Hong, H., 2007. Beneficial effects of Bacillus licheniformis on the intestinal microflora and immunity of the white shrimp, Litopenaeus vannamei. Biotechnol Lett, 29: 525-530.

Li, E., Chen, L., Zeng, C., Yu, N., Xiong, Z., Chen, X., Qin, J.G., 2008. Comparison of digestive and antioxidant enzymes activities, haemolymph oxyhemocyanin contents and hepatopancreas histology of white shrimp, Litopenaeus vannamei, at various salinities. Aquaculture, 274: 80-86.

Lightner, D.V., 1988. Vibrio disease of penaeid shrimp. In: Sindermann, C.J., Lightner, D.V. (Eds.), Disease Diagnosis and Control in North American Marine Aquaculture. Elsevier, Amsterdam, The Netherlands, pp. 42- 47.

Lin, C.K., 1995. Progression of intensive marine shrimp culture in Thailand. In: C. L. Browdy and J.S. Hpkins (ed.), Swimming through troubled water. Proceedings of the special Session on Shrimp farming, Aquaculture' 95. World Aquaculture Society, Baton Rouge, La, pp. 1323.

Liu, C.H., Tseng, M.C., Cheng, W., 2007a. Identification and cloning of the antioxidant enzyme, glutathione peroxidase, of white shrimp, Litopenaeus vannamei, and its expression following Vibrio alginolyticus infection. Fish \& Shellfish Immunology, 23: 34-45.

Liu, Y., Wang, W.N., Wang, A.L., Wang, J.M., Sun, R.Y., 2007b. Effects of dietary vitamin E supplementation on antioxidant enzyme activities in Litopenaeus vannamei (Boone, 1931) exposed to acute salinity changes. Aquaculture, 265: 351-358.

Livingstone, D.R., Lips, F., Garcia Martinez, P., Pipie, R.K., 1992. Antioxidant enzymes in digestive gland of the common mussel, Mytilus edulis L. Marine Biology, 112: 265-276.

Livingstone, D.R., 2001. Contaminant-stimulated reactive oxygen species production and oxidative damage in aquatic organisms. Mar. Pollut. Bull. 42, 656-666.

Lowry O., Rosebrough, N.J., Farr, AL., Randall, R.S., 1951. Protein measurements with Folin phenol reagent. J. Biol. Chem. 193, 265-275.

Lygren, B. and Hemre, G.I., 2001. Influence of dietary carbohydrate on antioxidant enzyme activities in liver of Atlantic salmon (Salmo salar L.). Aquaculture International, 9: 421- 427.

Lykkesfeldt, J., 2007. Malondialdehyde as biomarker of oxidative damage to lipids caused by smoking. Clinical Chimica Acta, 380: 50-58.

Manduzio, H., Rocher, B., Durand, F., Galap, C., Leboulenger, F., 2005. The point about oxidative stress in molluscs. ISJ 2: 91-104.

Marklund, S., and Marklund, G., 1974. Involvement of superoxide anion radical in the auto oxidation of pyrogallol and a convenient assay for superoxide dismutase, European Journal of Biochemistry, 47: 469-474.

Mermoud, A., Costa, R., Ferré, O., Goarant, C., Haffner, P., 1998. 'Syndrome 93' in New Caledonian outdoor rearing ponds of Penaeus stylirostris: history and description of three major outbreaks. Aquaculture 164, 323-335. 
Mourente, G., Diaz-Salvago, E., Bell, J.G., Tocher, D.R., 2002. Increased activities of hepatic antioxidant defence enzymes in juvenile gilthead sea bream (Sparus aurata L.) fed dietary oxidised oil : attenuation by dietary vitamin E. Aquaculture, 214: 343:361.

Muñoz, M., Cedeño, R., Rodríguez, J., Van der Knap,p W.P.W., Mialhe, E., Bachère, E., 2001. Measurement of reactive oxygen intermediate production in haemocytes of the penaeid shrimp, Penaeus vannamei. Aquaculture, 191:89-107.

Pan, C.H., Chien, Y.H.,, Hunter, B., 2003. The resistance to ammonia stress of Penaeus monodon Fabricius juvenile fed diets supplemented with astaxanthin. Journal of Experimental Marine Biology and Ecology 297, 107- 118.

Parvez, S., Raisuddin, S., 2005. Protein carbonyls: novel biomarkers of exposure to oxidative stress-inducing pesticides in freshwater fish Channa punctata (Bloch). Environmental Toxicology and Pharmacology, 20: 112-117.

Prior, R.L., Cao, G., 1999. In vivo total antioxidant capacity: comparison of different analytical methods. Free Radical Biology \& Medicine, 27: 1173-1181.

Rahmat, A., Fadzelly Abu Bakar, M., Hambali, Z., 2006. The effects of guava (psidium guajava) consumption on total antioxidant and lipid profile in normal male youth. African Journal of food agriculture nutrition and development, 6: 1:12.

Rameshthangam, P., and Ramasamy, P., 2006. Antioxydant and membrane bound enzymes activity in WSSV-infected Penaeus monodon Fabricius. Aquaculture, 254: 32-39.

Rengpipat, S., Rukpratanporn, S., Piyatiratitivorakul, S., Menasaveta, P., 2000. Immunity enhancement in black tiger shrimp Penaeus monodon by a probiont Bacillus S11. Aquaculture 191, 271-288.

Rodríguez, J., Espinosa, Y., Echeverría, F., Cárdenas, G., Román, R., Stern, S., 2007. Exposure to probiotics and $\beta-1,3 / 1,6$-glucans in larviculture modifies the immune response of Penaeus vannamei juveniles and both the survival to White Spot Syndrome Virus challenge and pond culture. Aquaculture 273, 405-415

Rosas, C., Cuzon, G., Gaxiola, G., Pascual, C., Taboada, G., Arena, L., van Wormhoudt, A., 2002. A energetic conceptual model of the physiological role of dietary carbohydrate and salinity on L. vannamei juveniles. J. Exp. Mar. Biol. Ecol. 268, 47-67.

Sagone A.L. Jr, Greenwald J., Kraut E.H., Bianchine J. and Singh D. 1983. Glucose: A role as a free radical scavenger in biological systems. Journal of Laboratory and Clinical Medicine 101: 97-103.

Söderhäll, K., Cerenius, L., 1998. Role of the prophenoloxidase-activating system in invertebrate immunity. Current Opinion in Immunology, 10: 23-28.

Stadtman, E.R., 1986. Oxidation of proteins by mixed function oxidation system: implication in protein turnover, aging and neutrophil function. Trends Biochem. 11, 11.

Storey, K.B., 1996. Oxidative stress: animal adaptation in nature. Brazilian Journal of Biological Research, 29: 1715-1733.

Vershuere, L., Rombaut, G., Sorgeloos, P., Verstraete, W., 2000. Probiotic bacteria as biological control agents in aquaculture. Microbiol. Mol. Biol. Rev. 64, 655- 671.

Vine, N.G., Leukes, W.D., Kaiser, H., 2006. Probiotics in marine larviculture. FEMS Microbiol. Rev. 30, 404-427.

Wabete N., Chim, L., Pham, D., Lemaire, P., Massabuau, J.C., 2006.A soft technology to improve survival and reproductive performance of Litopenaeus stylirostris by counterbalancing physiological disturbances associated with handling stress. Aquaculture 260, 181-193.

Wabete, N., Chim, L., Lemaire, P., Massabuau, J.C., 2008. Life on the edge : physiological problems in penaeid prawns Litopenaeus stylirostris, living on the low side of their thermopreferendum. Marine Biology 154, 403-412.

Wang, F.I., Chen, J.C., 2006. Effect of salinity on the immune response of tiger shrimp Penaeus monodon and its susceptibility to Photobacterium damselae subsp. Damselae. Fish \& Shellfish Immunology, 20, 671-681.

Winston, G.W., Di Giulio, R.T., 1991. Prooxidant and antioxidant mechanisms in aquatic organisms. Aquat. Toxicol. 19, 137-161. 
Zenteno-Savín, T., Saldierna, R., Ahuejote-Sandoval, M., 2006. Superoxide radical production in response to environmental hypoxia in cultured shrimp. Comparative Biochemistry and Physiology, Part C, 142, 301-308.

Zhang, O., Li, F., Zhang, X., Dong, B., Zhang, J., Xie, Y., Xiang, J., 2008. cDNA cloning, characterization and expression analysis of the antioxidant enzyme gene, catalase, of Chinese shrimp Fenneropenaeus chinensis. Fish \& Shellfish Immunology, 24: 584-591.

\section{Tables}

Table 1: Composition of the experimental diet

\begin{tabular}{|c|c|}
\hline Ingredients & $\%$ \\
\hline LT Fish meal ${ }^{(\mathrm{a})}$ & 30 \\
\hline Soy bean meal ${ }^{(\mathfrak{b})}$ & 20 \\
\hline Wheat meal ${ }^{(\mathrm{c})}$ & 37 \\
\hline Wheat Gluten & 7 \\
\hline Fish oil & 0 \\
\hline Soy oil & 2 \\
\hline Soy lecithin ${ }^{(d)}$ & 2 \\
\hline Shrimp vitamin premix ${ }^{(\mathrm{e})}$ & 0.05 \\
\hline Shrimp trace mineral premix ${ }^{(t)}$ & 0.1 \\
\hline Stay C (330 mg/kg) $)^{(\mathrm{g})}$ & 0.04 \\
\hline \multicolumn{2}{|c|}{ Compostion (analysed, dry matter basis) } \\
\hline $\operatorname{Protein}^{(1)}(\%)$ & 43.8 \\
\hline $\mathrm{Fat}^{(2)}(\%)$ & 10 \\
\hline Fiber $^{(3)}(\%)$ & 2 \\
\hline $\operatorname{Ash}^{(4)}(\%)$ & 6.9 \\
\hline Gross energy (Kcal.kg-1) & 4502 \\
\hline
\end{tabular}

${ }^{(a)}$ Chilean low temperature fish meal from anchovy and Jacl Marckerel

${ }^{(b)}$ Dehulled soybean meal solvent extracted

(c) Whole wheat grain for animal feed

(d) Ultrales ${ }^{\circledR}$ lecitin from ADM lecithin, Decatur, IL, USA

(e) Vitamin premix SICA Cie

${ }^{(f)}$ Mineral premix SICA Cie

(1) ISO5983 standard

${ }^{(2)} \mathrm{NF}$ V18-117/B standard

${ }^{(3)} \mathrm{NF}$ V03-040 standard

${ }^{(4)} \mathrm{NF}$ V18-101standard 
Table 2

\begin{tabular}{|c|c|c|c|c|c|c|c|}
\hline \multirow[b]{2}{*}{ Trial } & \multirow[b]{2}{*}{ day } & \multicolumn{2}{|c|}{ Survival (\%) } & \multicolumn{2}{|c|}{$\begin{array}{c}\text { Prevalence (\% of the } \\
\text { sampled shrimps infected) }\end{array}$} & \multicolumn{2}{|c|}{$\begin{array}{c}\text { Load } \\
\text { (number of } V . \text { nigripulchritudo } \\
\text { colonies/infected shrimp) }\end{array}$} \\
\hline & & Control & Probiotic & Control & Probiotic & Control & Probiotic \\
\hline \multicolumn{8}{|c|}{ trial 1} \\
\hline & day 0 & & & 0 & 0 & 0 & 0 \\
\hline & day 22 & $94 \pm 10^{a}$ & $96 \pm 8^{a}$ & 0 & 0 & 0 & 0 \\
\hline \multicolumn{8}{|c|}{$\underline{\text { trial } 2}$} \\
\hline & day 0 & & & 0 & 0 & 0 & 0 \\
\hline & day 11 & & & $90 \pm 15^{a}$ & $63 \pm 8^{b}$ & $41.5 \pm 16.6^{a}$ & $21.7 \pm 14.0^{b}$ \\
\hline & day 22 & $47 \pm 6^{c}$ & $64 \pm 7^{b}$ & $90 \pm 8^{a}$ & $45 \pm 12^{b}$ & $13.5 \pm 15.9^{c}$ & $8.6 \pm 2.6^{c}$ \\
\hline & $S^{(1)}$ & & & n.s & n.s & * & n.s \\
\hline
\end{tabular}

For each parameter, data within the same line with different superscript letters are significantly different $(p$ $<0.05)$. Values are tank means \pm s.d. $(n=4$, stars indicate "significant" differences between sampling times ( $\left.{ }^{*} p<0.05\right)$, n.s., non sifgnificant).

${ }^{(1)} \mathrm{S}=$ Significance

\section{Table 3}

\begin{tabular}{|c|c|c|c|c|c|c|}
\hline & \multicolumn{3}{|c|}{ trial 1} & \multicolumn{3}{|c|}{ trial 2} \\
\hline & Control & Probiotic & $S^{a}$ & Control & Probiotic & $S^{a}$ \\
\hline \multicolumn{7}{|l|}{ haemolymph } \\
\hline TAS $\left(\mu \mathrm{mol} . \mathrm{ml}^{-1}\right)$ & $0.33 \pm 0.01$ & $0.42 \pm 0.02$ & ** & $0,28 \pm 0.06$ & $0.56 \pm 0.07$ & ** \\
\hline $\operatorname{SOD}\left(U \cdot \mathrm{ml}^{-1}\right)$ & - & - & & $283.7 \pm 44.3$ & $153.7 \pm 25.4$ & ** \\
\hline \multicolumn{7}{|l|}{ Digestive gland } \\
\hline$\overline{\text { TAS }\left(\mu \mathrm{mol} . g \text { organ }^{-1}\right)}$ & $12.88 \pm 0.63$ & $14.98 \pm 0.46$ & * & $8.5 \pm 1.61$ & $13.25 \pm 1.50$ & * \\
\hline SOD (U.mg protein $\left.{ }^{-1}\right)$ & $1.28 \pm 0.07$ & $1.31 \pm 0.07$ & n.s & $3.53 \pm 0.52$ & $1.96 \pm 0.36$ & ** \\
\hline CAT $\left(\mu \mathrm{mol} \cdot \mathrm{min}^{-1} \cdot \mathrm{mg}\right.$ protein $\left.{ }^{-1}\right)$ & $0.62 \pm 0.03$ & $0.66 \pm 0.14$ & n.s & $3.08 \pm 0.75$ & $1.34 \pm 0.11$ & * \\
\hline GPX (nmol.min ${ }^{-1} \cdot \mathrm{mg}$ protein $\left.{ }^{-1}\right)$ & $13.85 \pm 0.17$ & $14.54 \pm 0.26$ & * & $69.5 \pm 8.0$ & $95.9 \pm 6.3$ & ** \\
\hline GSH (nmol.mg protein $\left.{ }^{-1}\right)$ & $3.15 \pm 0.38$ & $2.88 \pm 0.19$ & n.s & $4.43 \pm 0,62$ & $4.93 \pm 1.32$ & n.s \\
\hline GSSG/GSH & $0.22 \pm 0.03$ & $0.25 \pm 0.02$ & n.s & $0.58 \pm 0.07$ & $0.36 \pm 0.04$ & $\star \star$ \\
\hline
\end{tabular}

${ }^{\mathrm{a}} \mathrm{S}=$ Significance

Values are tank means \pm s.d. ( $n=4$, stars indicate "significant" differences between treatments ( $\left.{ }^{*} p<0.05,{ }^{* *} p<0.01\right)$, n.s., non sifgnificant). 
Table 4

\begin{tabular}{|c|c|c|c|c|c|c|}
\hline & \multicolumn{2}{|c|}{ trial 1} & \multicolumn{4}{|c|}{ trial 2} \\
\hline & Control & Probiotic & $\mathrm{S}^{\mathrm{a}}$ & Control & Probiotic & $S^{a}$ \\
\hline MDA (nmol.g organ $\left.{ }^{-1}\right)$ & $85.1 \pm 6.5$ & $78.4 \pm 13.0$ & n.s & $99.3 \pm 16.0$ & $70.8 \pm 15.6$ & $\begin{array}{c}\text { n.s. } \\
p=0.06\end{array}$ \\
\hline Carbonyl protein (nmol.mg protein ${ }^{-1}$ ) & $4.03 \pm 0.40$ & $4.82 \pm 0.35$ & n.s & $7.71 \pm 0.99$ & $3.01 \pm 0.63$ & $* \star *$ \\
\hline
\end{tabular}

${ }^{\mathrm{a}} \mathrm{S}=$ Significance

Values are tank means \pm s.d. $(n=4$, stars indicate "significant" differences between treatments $(\star \star \star p<0.001$, n.s., non sifgnificant).

\section{Figures}

Figure 1. Cumulative mortalities of control and probiotic treated shrimps during both experiments.

Trial 1

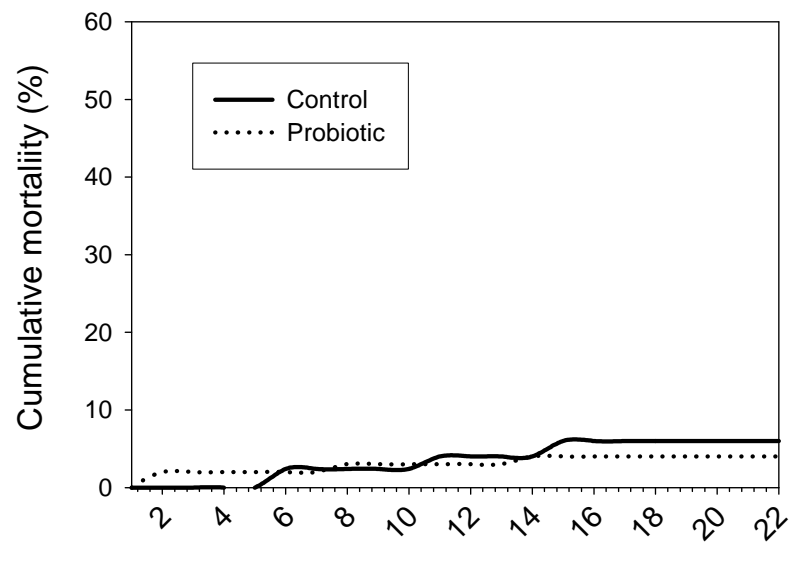

Days of rearing
Trial 2

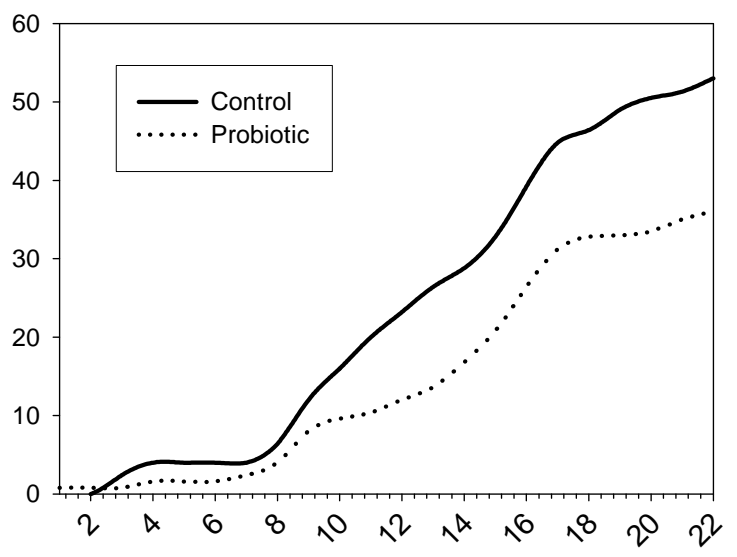

Days of rearing 